\title{
Mega-events and Tourism Impacts: Foreign Visitor Perceptions of the 2010 FIFA World Cup in South Africa
}

\author{
Urmilla Bob $^{1}$ and Cheryl Potgieter ${ }^{2}$ \\ ${ }^{1}$ School of Environmental Sciences, University of KwaZulu-Natal, Westville Campus, \\ Durban, South Africa \\ E-mail: bobu@ukzn.ac.za \\ ${ }^{2}$ University Dean of Research, University of KwaZulu-Natal, Durban, , South Africa \\ E-mail: deanofresearch@ukzn.ac.za
}

KEYWORDS Sport Tourism. Tourism in South Africa. Destination Profiling. Costs and Benefits. Legacies

ABSTRACT There are several impacts of hosting events that relate to economic and social development aspects. South Africa has used sport tourism to promote the country as a major sports events destination. Research on mega-events tends to focus on economic impacts, including tourism effects. Very few, however, examine visitor perceptions of the event to establish experiences and concerns. This article examines the positive and negative relationships between tourism and the hosting of mega-events with a special focus on the 2010 FIFA World Cup, Africa's first mega-event. Additionally, visitor perceptions derived from interviews undertaken with 4814 foreign tourists during the World Cup are examined. The results reveal that foreign visitors generally enjoyed their stay in South Africa and perceived the country as a good tourism destination. The article concludes that tourism outcomes related to the hosting of mega-events need to be planned, particularly if more widespread benefits are to be realised within the tourism industry and in local communities. In particular, the positive experiences and images of South Africa as a result of the World Cup should be integrated into an appropriate destination marketing strategy.

\section{INTRODUCTION}

There are several intended and unintended impacts of hosting events that relate to economic benefits, increased destination awareness, increase in investor potential, infrastructural development and social aspects. South Africa is a long-haul tourist destination with unique environmental and cultural tourism products. The country has also increasingly used sport tourism to promote South Africa as a major sport events destination hosting the Rugby, Cricket and prestigious FIFA World Cups since the 1994 democratic elections. Utilising large-scale sport events (including mega-events such as the 2010 FIFA World Cup and expressed desire to host the Olympic Games in the future) has become an important tourism strategy in South Africa. South Africa's successful bid and hosting of the 2010 FIFA World Cup was linked directly to leveraging economic benefits, including attracting tourists during the event and profiling South Africa as a tourist destination. The latter is intended to ensure long-term tourism legacy impacts. While a significant amount of research focuses on the anticipated and actual economic impacts of mega-events, including tourism economic assessments, few examine longer term tourism impacts and visitor perceptions of the event to establish experiences and concerns that can inform future destination marketing and tourism strategies.

This article critically examines the positive and negative tourism impacts and legacies associated with the hosting of the FIFA World Cup, specifically in relation to foreign visitor perceptions of the 2010 FIFA World Cup. The focus is on South Africa as a tourist destination and on legacies, which are deemed to be part of ensuring long term benefits after the event is hosted. These are neglected areas of research since most studies focus on impacts during the event. This article draws on relevant literature and primary data from foreign visitor surveys conducted during the World Cup. The article demonstrates that the anticipated visitor numbers were not realised during the World Cup, linked in part to South Africa being a long-haul destination and the global economic recession experienced. Furthermore, the increase in accommodation and transport costs may have positioned South Africa as an expensive tourist destination which may in the long-term dissuade tourism travel. Additionally, concerns are raised in relation to who benefits from mega-event tourism and interactions with local communities. However, shifts in emerging markets (for example, a significant proportion of the visitors were from the 
United States of America and Asia which are new markets for South Africa) provide tourism opportunities linked to the World Cup.

The next section examines key issues in relation to mega-events and tourism. This is followed by a brief overview of the methodological approach adopted to undertake the primary research used in this study. The next section presents and analyses the results from the primary data collected. Finally, concluding comments and recommendations are forwarded.

\section{Mega-events and Tourism}

Due to the complexity of concepts and aspects pertaining to tourism and mega-events, a single theoretical approach is inadequate. It is therefore important to consider multiple theories and perspectives that assist in identifying the complexity of aspects and contextualise impacts which can differ depending on the circumstances. This article draws on key concepts and explanations to examine tourism issues in relation to the hosting of mega-events. Meethan (2001) notes that tourism is often viewed as part of the process of commodification and consumption inherent in modern capitalism involving flows of people, capital, images and cultures. There is no doubt that sport mega-events are part of big business. In this article global aspects are considered since tourism is largely a global activity with a range of drivers and constraints.

The hosting of mega-events is embedded in high levels of global competition (Cornelissen 2010) and generates benefits and costs for different groups and localities. Van Der Merwe (2007) states that mega-events which are hosted in developing countries can be termed a mixed blessing since, although they may bring the promise of numerous economic benefits and the hope of uplifting the host nation in a number of ways, these events also tend to be the source of much controversy, and if not carefully planned, can lead to enormous financial losses. Undoubtedly, the main justification to host mega-events is the economic benefits which are deemed to be important to achieve developmental and social objectives. However, Bob and Swart (2010a) highlight that in relation to the economic impacts projections are often based on ex-ante studies and reports that tend to inflate anticipated outcomes and impacts. They further state that long- term economic impacts of mega-events tend to be ignored. Local Economic Development (LED) is therefore also important to consider local impacts in relation to destination profiling and tourism revenues. The distribution of benefits and issues pertaining to reinforcing inequalities are examined as well.

The sustainability framework promotes that environmental aspects and longer-term legacies are considered. Getz (2005: 123) states that "sustainable events are those that can endure indefinitely without consuming or spoiling the resources upon which they depend”. However, Cornelissen et al. (2011) underscore that considerations of sustainability usually require a long-term (20+ year) outlook and necessitate a holistic and integrated view at different levels (global to local). They argue that mega-events are by their very nature intense and of fixed duration.

A humanist approach encourages the focus on experiences and perspectives. This informs the decision to incorporate tourists' perceptions. Tourists are deemed to be a key stakeholder, especially in relation to examining tourism impacts. The brief discussion above illustrates that multiple perspectives are required to examine the range of issues relating to mega-events and tourism. Using the multiple frameworks presented above, this section discusses tourism generally and then specifically focuses tourism trends and issues in South Africa. Then, South Africa's hosting of the 2010 FIFA World Cup and tourism implications are discussed.

\section{Tourism}

Tourism is one of the largest industries in the world. Specifically, the United Nations World Tourism Organisation (UNWTO) (cited in South African Tourism (SAT) 2011) states that worldwide, international tourist arrivals grew by $6.7 \%$ in 2010 to 935 million. This increase is largely derived from growth in the emerging markets in developing countries (8\%), including South Africa, while advanced markets grew by $5 \%$. UNWTO (2010) states that the positive trends follow one of the toughest years for the tourism sector with international tourist arrivals declining by $4.2 \%$ in 2009 to 880 million and international tourism receipts reaching US\$ 852 billion, a decrease in real terms of $5.7 \%$. According to the World Travel and Tourism Council (WTTC 
2007), tourism and travel accounts for $10 \%$ of the world's Gross Domestic product (GDP), 8\% of jobs and $12 \%$ of global investments annually. Furthermore, the WTTC (2007) states that this sector has the highest potential for growth of any industry averaging $4 \%$ per annum worldwide, $3 \%$ in developed economies and more than $7 \%$ in emerging countries. It therefore is well positioned to advance economic development in developing countries. Tourism is perceived as an important job creator because it is labour intensive and service orientated that diversifies the economy of a country and brings in foreign revenues. It creates significant induced (that is, can encourage other sectors to develop such as the craft industry) and indirectly impacts (that is, relies on supplier industries such as food, marketing, transportation, communication and construction) that spreads economic benefits and opportunities. Mega-events are often associated with job creation. However, Chappelot and Junod (2006) caution that most of the jobs created are seasonal and/ or temporary. They assert that when considering employment generation as an economic legacy of an event the focus should be on the number of permanent jobs created and changes in the unemployment rate of the host region or city.

Several researchers have highlighted the advantages of tourism (which is also important in relation to sport tourism) (Bob and Swart 2010a; Page and Hall 2003; WTTC 2007):

- It has a relatively high-income elasticity and therefore offers a rapidly growing market. The WTTC specifically states that the tourism industry is resilient and is able to cope with successive challenges such as terrorism and disease (WTTC 2007). From the statistics presented earlier, it is clear that the tourism industry appears to be one of the few sectors recovering from the current economic recession, showing growth worldwide.

- It is a labour intensive industry, which uses a high level of unskilled labour. Where skills are required, this training is usually easily acquired.

- Linked to skilling, tourism events in particular provide the opportunity for skills development and upskilling of human resources in the tourism sector. This can include event management capacity that contrib- utes to future successful bidding and hosting for events as well as improving service quality and policing (this was a key focus during the preparations for the FIFA World Cup in South Africa) which have positive impacts on tourist experiences. These opportunities are increased during megaevents which are associated with high levels of voluntarism and programmes targeting historically disadvantaged groups.

- Tourism has many linkages to a wide variety of other industries and hence it has the potential for a high multiplier effect on income. In addition, it has a diversifying effect on the economy which is particularly important in developing contexts.

- Tourism depends on the identification of a specialised product and the creation of specialised demand. The conditions for stimulating this sector and the products of the sector appear to be less demanding than that of other sectors.

- Tourism and tourists often do not face quotas or tariffs and hence the level of government controls is limited.

- Self-marketing in that tourists themselves who have positive experiences market the destination via word-of-mouth, which for developing countries such as South Africa remains critically important. Simpson and Siguaw (2008) identify word-of-mouth as being a salient aspect in relation to satisfaction when profiling a destination. Thus, personal experience is an important component of marketing and promoting repeat visitation.

- Other aspects of a destination are also profiled which can change the perception of a country. Bob and Swart (2010a) illustrate that the 2006 FIFA World Cup provided Germany with an opportunity to change well established perceptions internationally of a Nazi, divided Germany. They also state that the hosting of large-scale sport events in South Africa such as the 1995 Rugby World Cup, 2003 Cricket World Cup and 2010 FIFA World Cup reinforced the country's post-apartheid transition in the global arena. Specifically, the successful hosting of the World Cup without major criminal incidents has assisted in challenging widely held perceptions globally that South Africa is the crime capital of the world. 
However, tourism can also have significant negative impacts which include the following:

- A significant proportion of foreign tourist expenditure is on accommodation and travel. This is often purchased in the country of origin where most of the profits are retained. Furthermore, as Meethan (2001) states, large-scale multinational companies, which are privately owned, dominate the sector although most have franchises or joint ownership with local companies.

- The impact on local cultures and values can also be negative and include concerns relating to social disruptions (increases in crime, prostitution, drug-peddling); inconveniencies (increase in traffic congestion and overcrowding) and cost escalation of goods and services. The impact on communities also includes concerns relating to the staging of local cultures for tourist consumption and entertainment that erodes the authenticity of indigenous cultures. In some instances the hosting of a mega-event results in forced removals to accommodate infrastructural development (Bob and Swart 2010a).

- A growing concern, especially given the consistent increase in tourism worldwide and the magnitude of events, is the environmental impacts (Ahmed and Pretorius 2010; Schmied et al. 2007). This is also linked to issues relating to the carrying capacity of ecosystems, infrastructure and services.

- Often tourism products are geared towards the high-end international markets and locals cannot afford the tourist experience. Competition for goods and services as well as augmented demand (especially from foreigners who have more disposable income) pushes up local prices which results in locals being unable to afford these goods and services. This is particularly noticeable during mega-events when tickets, transportation and accommodation prices soar to maximise profits.

- A major concern in relation to tourism is the distribution of benefits which remain in the hands of a few, generally those from historically advantaged groups (in South Africa mainly Whites and the rich benefit). This was a concern raised during the FIFA World Cup regarding whether economic benefits will reach the poor.
Getz (2005) identifies key reasons and objectives for destinations investing in special events and promoting its growth:

- To attract visitors into the area and ensure that it is on the tourist map;

- To attract visitors outside the main tourist season to reduce seasonality, troughs and underutilisation of tourism infrastructure;

- To attract media attention, raise the profile of the area, create a favourable image, combat negative images and thereby attract investment from outside the area;

- To encourage repeat visits; and

- To develop niche markets in a developing marketplace.

As can be deduced from the above, the main focus is not on tourist arrivals during the event but on destination profiling and marketing to leverage benefits after the event.

\section{Tourism in South Africa}

South Africa with its physical location and natural features including a variety of ecosystems and natural environments, unique history, diverse cultures, and range of tourism products makes it an attractive destination for different markets. Although there remain debates in the literature about the different categories/ types of tourism, the following are some of the key types driving tourism in South Africa: ecotourism; Meetings, Incentives, Conferences and Exhibitions (MICE or business market); visiting friends and family; wine tourism; cultural and heritage tourism; and events tourism. In relation to the latter, a key component and increasing important focus in South Africa is sport tourism. Tourism in South Africa is aimed at increasing market share and enhancing the contribution that this sector makes to "the country's economic development and enables economic and social empowerment and upliftment” (Cornellissen 2005: 43).

Kromberg (2003) states that in South Africa travel and tourism is estimated to account for 6.6 percent of total employment. The Highlights of Tourism's Performance in 2010 report (SAT 2011) illustrates that during 2010 tourists arrivals in South Africa grew by $15.1 \%$ (well above the global average of $6.7 \%$ with $8,073,552$ tourists in total). The report indicates that foreign tourist arrivals to South Africa was boosted by the 2010 FIFA World Cup which saw 309,554 
tourists arrive specifically for the event and spend in excess of R3,64 billion. Furthermore, World Cup tourists on average stayed for longer periods. The most significant growths were experienced in Central and South America (109.2\% up from 2009), Asia (39.1\% up from 2009), Australasia (26.2\% up from 2009) and North America (22.5\% up from 2009). In particular, the Americas (37.4\%) and Asia and Australasia (34.6\%) grew the fastest in 2010. The least increase was experienced in Europe (8.1\% up from 2009), South Africa's main foreign tourist market. This shows that South Africa's hosting of a mega-event exposed the country to new markets, a major tourism growth strategy. However, the UK, USA, Germany, Netherlands and France remain the top five overseas source markets.

The South African tourism industry, according to the WTTC (2007), is characterised by a foreign tourist market which is made up of a significant land based travel component from neighbouring countries and an overseas market, which travels by air. Additionally, there is a significant domestic tourist component, which is higher volume but lower value than the overseas market but compares favourably with the foreign land based travel market. SAT (2011) identifies economic constraints as the greatest barrier cited by South Africans that prevented them from travelling in 2010 (31\% indicated that they could not afford to travel). Domestic tourism decreased by $2 \%$ in 2010 (with 29.7 million trips being undertaken compared to 30.3 million trips in 2009) and domestic spend decreased by 6\% (SAT 2011). The domestic travel incidence among the adult population dropped to its lowest level since 2007. Domestic tourists are the mainstay of the South African tourism system. The statistics reveal that the hosting of a mega-event displaces tourists either because of price escalation or normal tourists being dissuaded to travel because of a lack of interest in the FIFA World Cup and concerns over the magnitude and activities associated with the event. International tourist displacement was also likely to have occurred and is often associated with the hosting of mega-events with tourists unwilling to deal with the congestion and price increases often associated with these types of events.

SAT (2007, 2011) identifies the main positive and negative features of South Africa as a tourist destination derived from tourist and business responses. The main negative features are that South Africa is a long-haul destination for key source markets (Europe, North America and Asia), safety and security levels, and poor service quality. The main positive features were a variety of tourism products (many of which are unique); value for money destination; interesting, friendly cultures; and scenic destinations. The issue of South Africa being a long-haul destination is important to consider from an environmental perspective. Peeters and Scouten (2006) illustrated that long-haul tourists accounted for less than 255 of tourism revenues but were responsible for $70 \%$ of the ecological footprint of inbound tourism to Amsterdam. This is an illustrative example of the environmental impacts of long-haul travellers. Additionally, megaevents attract substantial visitor numbers and are associated with massive infrastructural development which impacts on the environment as well, as illustrated by Ahmed and Pretorius (2010).

\section{South Africa's Hosting of the 2010 FIFA World Cup and Tourism}

The 2010 FIFA World Cup was the first megaevent hosted on the African continent. The Bureau for Economic Research (2010: 3) indicates that that the 2010 World Cup "was a logistical success, much enjoyed by hosts and guests alike and favourably received by the world's media”. In addition to the advantages identified above of tourism generally, the hosting of mega-events particularly in developing countries are deemed to increase infrastructural development and investments, and profile the destination at a level that normal tourism marketing cannot achieve. Tourist arrival figures for South Africa in 2010 presented earlier shows that this did increase during 2010 when compared to previous periods and trends. Preuss (2007, 2011), cautions against tourism displacement and crowding-out effects (that is, the reduction on private consumption as a result of increased demand) that often occur. He argues that ignoring these impacts results in an over-estimation of tourism economic impacts. An example of these effects, as indicated earlier, is the decrease in domestic tourism during the World Cup.

The 2010 FIFA World Cup was the peak of post-apartheid South Africa's attempt to profile the country as a sport tourism destination and more broadly, an events-driven economy. Swart 
and Bob (2004) assert that the hosting of major events is a key component of South Africa's tourism strategy. Specific examples of previous sports events are the 1995 Rugby World Cup, Cape Town's 2004 Olympic Bid and the 2003 Cricket World Cup as well as established international annual sports events such as the Comrades and Two Oceans Marathons, Duzi Canoe marathon and Cape Argus Cycling Tour. Examples of major non-sport events include the Cape Jazz festival, Grahamstown Arts Festival and the Tourism Indaba. Events are therefore being used to promote socio-economic development. Cornelissen and Swart (2006) assert that sport events in particular are regarded as a mechanism to support the government's nation-building project and as economic and development catalysts. In relation to the World Cup, it had a unique developmental thrust. Unlike previous World Cups, Jordaan (2005) highlights that a key priority for South Africa was ensuring a social legacy, specifically an opportunity to leverage 2010 to promote nation-building, development, brand-building and African solidarity.

As indicated earlier, from an economic perspective and the main justification for massive public investments often associated with the hosting of mega-events are the tourism impacts before, during and after the event. Before the event, international travel is associated with event preparations, media interest and pre-event and build-up activities such as the 2009 Confederations Cup held in June and the FIFA World Cup Final Draw held in Cape Town, December 2009. During the main event tourists (spectators as well as accompanying friends and relatives) are attracted primarily to host cities to watch matches live and participate in once-in-a-lifetime experience. There is also massive media attention (in 2010 more than 15000 media arrivals were recorded) and the teams themselves have significant numbers. During the World Cup 32 teams participate from all regions of the World. After the event the most enduring tourism legacy is expected with increased tourist arrivals. This is as a result of the host destination receiving massive media attention and coverage (the FIFA World Cup has the largest global viewership globally), entering new markets and exposing the World to South Africa's tourism products.

An additional benefit is challenging negative perceptions and in the case of South Africa, the successful hosting of the event with any major safety and security incident certainly challenged widespread attitudes that South Africa is the world's crime capital. Steyn et al. (2009) illustrate that the key issues in the build up to the 2010 FIFA World Cup was the negative impacts of high levels of crime in South Africa and the concerns that this was likely to deter tourists from visiting the country. This was by far the most prevalent negative perception of South Africa as a tourist destination. However, crime rates did not drop during the World Cup but was displaced to non-tourist areas where locals were concentrated. A concern raised by Swart et al. (2010) is that the safety and security strategy implemented during the World Cup was mainly to keep event locations and tourists safe and a real concern was that the 2010 safety and security strategy would protect visitors at the expense of most South Africans. Furthermore, commonly raised questions relate to why such levels of resources cannot be deployed to keep South Africa safe for all and whether this level of security can be sustained after the event.

Focusing on mega tourism events can shift resources from the local populace and their needs (which are dire given widespread poverty and developmental challenges in South Africa). For example, as Cornelissen et al. (2011) indicate, events may leave hosts with escalating public debt which was the case for the city of Montreal, host to the 1976 Summer Olympics, where it took the city three decades to pay off the debt generated by the Games. They also state that there is insufficient support for the claim that events can lead to immediate tourism and investment gains for hosts. They assert that there is typically a time-lag of several years before a host's tourism sector may display growth. Additionally, often local residents have to cover shortfalls as price escalations push up infrastructural costs and underused facilities such as stadiums have to be subsidised by the tax base. This continues to move resources away from the poor. Cornelissen et al. (2011) assert that what is needed is an overall events strategy (including a mega-event component) that examines sustainability imperatives and provides a framework for communities to leverage and sustain benefits associated with the World Cup. Furthermore, as Getz (2005) cautions, a poor megaevent can impact negatively on the image and finances of the city as well as the country and 
will damage the countries chances of hosting mega-events in the future. Mega-events which concentrate the spotlight on a specific location therefore have the potential to reinforce negative stereotypes if things go wrong.

Since destination profiling is one of the main tourism benefits associated with the World Cup, this article examines tourists' perceptions during the event in relation to South Africa. The next section provides a brief overview of the methodological approach adopted and this is followed by the data analysis of the primary results.

\section{METHODOLOGY}

The article examines results from national visitor surveys undertaken during the FIFA World Cup (11 June to the 11 July 2011). Faceto-face interviews were conducted in fan parks and tourist information centres (for example, in airports and main tourism sites such as national parks) during the event in all nine provinces by trained volunteers who were part of the Department of Environmental Affairs and Tourism's (DEAT) National Volunteer Programme. A purposive sampling approach was adopted and 4,814 foreign tourists were interviewed in specific sites. However, to increase representation, the sampling framework included a geographic spread across all locations in which volunteers were placed and surveys were conducted during different times of the day. A total of 15,066 interviews were successfully completed. The rest of the respondents were locals or domestic tourists. This study focuses primarily on the foreign tourists.

In terms of the data analysis, descriptive statistics (frequencies) are presented in Tables to illustrate the findings derived from the questionnaire surveys. The percentages were rounded off to the nearest decimal point and this often resulted in the total percentage either being slightly less than or exceeding $100 \%$ by a few decimal points. The open-ended question that solicited suggestions for the future generated a range of responses which are also presented in relation to the main responses.

\section{RESULTS AND DISCUSSION}

This section presents and analyses the data gathered via the interviews. The socio-demo- graphic profile of the respondents is presented followed by an examination of foreign visitors' use of accommodation facilities. Visitation is then discussed in relation specifically to whether they visited South Africa before, will they return and will they recommend South Africa as a tourist destination. Their attitudes to South Africa and aspects related to their World Cup experience are examined next. Lastly, suggestions forwarded by the respondents to improve the event in the future and implications for tourism are addressed.

\section{Demographic Profile of Respondents}

The respondents were generally males (63.8\%) and were 18-80 years old with an average age of 34.8 years. The results closely resemble the profile of sport mega-event visitors who tend to be younger males. The monthly income of the respondents averaged R32, 349 and ranged from R2, 500 to R805,000. This reveals that middle and upper income respondents attended the World Cup. This is also reflected in the educational levels of the respondents presented below. The majority of the respondents had certificates/ diplomas (23.2\%), undergraduate degrees (22.3\%) and postgraduate degrees (42.3\%). This is expected given that South Africa is a long-haul destination and on average football fans travelling to the World Cup spent 16 days in the country (SAT 2011). This is clearly discernible in Table 1 which shows levels of education and corresponding percentages.

Table 1: Highest educational level attained (in $\%, n=4$ 814)

\begin{tabular}{lr}
\hline Level of education & Percentages \\
\hline No formal education & 1.5 \\
Primary completed & 0.7 \\
Secondary completed & 10 \\
Certification/ diploma & 23.2 \\
Undergraduate degree & 22.3 \\
Postgraduate degree & 42.3 \\
\hline
\end{tabular}

As shown in Table 2, among the foreigners, most were from Europe (37.8\%), the rest of Africa (17.6\%) and South America (17\%). This is followed by North America (11\%), Asia (8.3\%) and Australia/ New Zealand (7\%) with a few respondents from the Middle East (1.2\%). Europe, North America and the rest of Africa are the main 
source markets of travel for South Africa. As indicated earlier when presenting SAT (2011) statistics, the World Cup provided an opportunity for South Africa to enter new markets (especially South America, Asia and the Middle East).

Table 2: Permanent place of resident of respondent (in \%, $n=4$ 814)

\begin{tabular}{lc}
\hline Place/country of residence & Percentages \\
\hline Africa & 17.6 \\
Asia & 8.3 \\
Australia/ New Zealand & 7 \\
Europe & 37.8 \\
Middle East & 1.2 \\
North America & 11 \\
South America & 17 \\
\hline
\end{tabular}

\section{Use of Accommodation Facilities}

The visitors used a variety of accommodation types. The main types of accommodation facilities tourists interviewed stayed in were private accommodation, guesthouse/ bed and breakfast establishments, private room/ flat/ house rental, 1-3 star hotels and 4-5 star hotels as one notes in Table 3, the majority of the respondents stayed in paid accommodation of some form (75.8\%). The rest stayed with either friends/ family or camped/ stayed in a car. This reveals that as expected the accommodation industry benefits considerably from the hosting of a mega-event. Given that in excess of 300,000 tourists came to South Africa specifically for the World Cup, if our sample is representative of this population, it translates into approximately 227,400 tourists staying in paid accommodation.

Table 3: Type of accommodation used by respondent (in $\%, n=4$ 814)

\begin{tabular}{lr}
\hline Type of accommodation & Percentages \\
\hline Private accommodation & 17.2 \\
$\quad$ (friends/family) & 14.5 \\
Private room/ flat/ house rental & 5.5 \\
Car/ camping & 26.6 \\
Guesthouse/ bed and breakfast establishment & 18.4 \\
1-3 star hotel & 16.6 \\
4-5 star hotel & 0.3 \\
Other & 0.8 \\
No response & \\
\hline
\end{tabular}

As per Table 3, more than half of the respondents (53.7\%) stayed in accommodation that was further than $25 \mathrm{~km}$ from the closest stadium where 2010 games where being held. This could suggest that accommodation was more affordable away from the stadiums. As indicated earlier, a major concern of hosting mega-events is price escalation. Additionally, Ahmed and Pretorius (2010) warn that mega-events can have serious environmental consequences of which the carbon footprint related to transportation to the destination and within the country (especially of a mega-event such as the World Cup that has 9 host cities/ venues) is the biggest concern. This is also particularly important to consider in South Africa which is a long-haul destination.

\section{Visitation to South Africa}

Most foreign visitors (63.8\%) indicated that it was their first visit to South Africa while 36.3\% stated that they had visited South Africa before. Repeat visitation, as indicated by Alegre and Cladera (2006), is an important indicator of successful marketing and tourism potential of a region. Furthermore, client loyalty is established which promotes sustainability in the longerterm. With more than a third indicating repeat visitation in this survey, it is clear that a significant proportion had visited South Africa before and were satisfied with their experience to return, indicative of South Africa's profile as an attractive tourist destination. Close to two-thirds of the visitors were first-timers which supports SAT's (2011) assertion that the hosting of this mega-events in South Africa exposed the country to new markets.

Almost all the foreign respondents (95.7\%) indicated that they will visit South Africa again. This again indicates that they enjoyed their stay in South Africa and had a positive experience. This is also reflected by the findings that $97.8 \%$ of the foreign visitors stated that they will recommend South Africa as a tourist destination to friends and family.

\section{Attitudes towards South Africa}

Table 4 presents respondents' attitudes towards South Africa in relation to the destination as a tourist location and perceptions regarding the impacts of the World Cup. Most of the foreign respondents agreed or strongly agreed with the statements South Africa is a beautiful area 
(94.3\%), the locals are friendly (89.9\%), the infrastructure is good (79.3\%) and that the quality of service is good (84.5\%). The positive attitudes towards the locals could be attributed to the higher levels of social interactions and the celebratory nature of the event itself. Respondents expressed positive attitudes towards infrastructure and service quality. These are aspects were focused on in preparations for the World Cup and appear to have reaped benefits.

A significant proportion of the foreign respondents agreed or strongly agreed with the statement that crime is a problem (35.5\%). While $22.4 \%$ of the respondents strongly disagreed or disagreed with this statement, $42.4 \%$ were neutral. The latter responses could be attributed to pre-existing perceptions influencing the respondents. As SAT (2010) shows, the main concern identified by tourists visiting South Africa relates to safety and security aspects. This emerges from exit interviews and is a perception that persists despite visitors not personally experiencing any incidents of crime.

As indicated earlier, the hosting of a megaevent can have major tourism benefits in terms of image enhancement and destination profiling. In the South African context a major concern is the impacts of crime in society and on the tourism industry specifically. Cornelissen and Maennig (2010) assert that nation building and social cohesion associated with the 'feel-good factor' of hosting a mega-event is the most tangible component of hosting the World Cup experienced by most South Africans and visitors. Thus, it is possible that mega tourism events can have a positive impact on creating a safer society which in turn will attract more tourists to the country.

The responses in Table 4 generally reveal that the majority of the respondents associate the World Cup with areas becoming more polluted (74.8\% agreed or strongly agreed with the statement) and noise levels increasing (79.1\% agreed or strongly agreed with the statement). Thus, respondents associated the event with negative environmental impacts which support the literature. Ahmed and Pretorius (2010) and Schmied et al. (2007) specifically indicate that large-scale sporting events such as the World Cup leave a massive carbon footprint.

The respondents felt that there were high noise levels which are expected during the World Cup. However, it is unclear whether respondents associated these concerns (including increased pollution) with the event specifically, or with South Africa more generally. This aspect was not probed further. As illustrated in earlier discussions, the hosting of mega-events can bring about negative perceptions and experiences because of the very nature of the event. Both locals and foreigners attended the Fan Parks and other public viewing areas. Bob and Swart (2010b) assert that these locations emerged as key spaces for residents and tourists to experience the event outside the stadiums. The World Cup created spaces for interactions that do not exist during periods of normal travel.

The vuvuzelas in particular emerged as the main contributor to the high noise levels. However, from a tourism perspective, it became a national symbol for South Africa's celebration of the World Cup worldwide. It is used in several marketing campaigns and has become an important aspect of branding South Africa as a fun and passionate sport tourism destination. While there were reports of foreign tourists not being able to enjoy matches because of the noise levels associated with the vuvuzelas, for the most part they joined in the festivities and added their own cultural symbols. For example, the Dutch travelled with their cow bells.

\section{Suggestions to Improve the Event in the Future}

Respondents forwarded several suggestions to improve the event in the future, of which the

Table 4: Attitudes towards South Africa in relation to level of agreement with specific statements

\begin{tabular}{lccccr}
\hline Attitudes towards South Africa & $\begin{array}{c}\text { \% Strongly } \\
\text { disagree }\end{array}$ & \% Disagree & \% Neutral & \%Agree & $\begin{array}{c}\text { \%Strongly } \\
\text { agree }\end{array}$ \\
\hline South Africa is a beautiful area & 1.6 & 0.7 & 3.2 & 31.7 & 62.6 \\
The locals are friendly & 1.3 & 1.2 & 7.5 & 40.8 & 49.1 \\
The infrastructure is good & 1.2 & 3 & 16.4 & 49.9 & 29.4 \\
The quality of service is good & 1.4 & 1.6 & 12.9 & 50 & 34.1 \\
Crime is a problem & 6.9 & 15.5 & 42.4 & 23.1 & 12.1 \\
Areas are more polluted during the World Cup & 1.9 & 8 & 15.2 & 41.4 & 33.4 \\
Noise levels increase during the World Cup & 2.3 & 5.7 & 12.9 & 35.6 & 43.5 \\
\hline
\end{tabular}


main ones where improving advertising, transportation infrastructure, signage and services. Additionally, more accessible information and developing local communities were suggested. A main recommendation was reducing the cost of accommodation and food. Mega-events are associated with price escalations which can have serious consequences for the tourism industry. During the 2010 FIFA World Cup, for example, the massive increases in accommodation and travel costs resulted in many accommodation facilities experiencing lower than average occupancy rates as compared to the similar period during previous years.

Foreign tourists also seemed to notice the high levels of poverty that exist in South Africa within specific communities and suggested that this should be a key focus. Thus, the quality of life of local's impact on the perceptions of a country. It is important to note that only a few respondents identified improving safety and security measures. This is unlike previous studies (see for example, George 2003, 2010) where one of the main concerns of South Africa as a tourist destination is crime. This supports Swart et al.'s (2010) assertion that safety and security measures were significantly improved during the World Cup.

\section{CONCLUSION}

The results reveal that foreign visitors generally enjoyed their stay in South Africa, had positive experiences and perceived the country as a good tourism location. Almost all respondents indicated that they will visit South Africa again, reinforcing high levels of satisfaction. Tourists raised concerns in relation to crime (linked largely to perceptions rather than actual experiences) and costs.

The successful hosting of major events is indicative of existing and potential tourism capacity and capability within South Africa. Furthermore, tourism impacts linked to the hosting of mega-events is an important long-term legacy. This article reveals that issues are complex and require multidisciplinary frameworks and theories to inform a better understanding of the impacts and the implications thereof. Furthermore, diverse methodological approaches are required to unpack issues and concerns from differing stakeholder perspectives. Clearly, a range of issues such as economic, social, polit- ical and environmental considerations need to be reflected on when focusing on mega sport events and tourism impacts.

There are complex interactions that result in context-specific and changing benefits and costs associated with hosting mega-events. However, very few studies monitor this aspect to establish the nature and extent of these impacts. This type of research is critical to examine long-term tourism gains, especially in developing countries like South Africa where massive public funds are invested. It is therefore imperative that continuous research be undertaken to examine long-term trends to assess whether anticipated tourist returns on investment are realised. This should inform future mega-event bidding plans which should reflect on the gains and losses associated with the hosting of the FIFA World Cup. This is critically important in developing countries. There is already an interest in some quarters in South Africa (particularly recently the City of Durban and the Ministry of Sport and Recreation South Africa) to bid for the Olympic Games. Yet, a rigorous and critical assessment of the impacts of the 2010 FIFA World Cup is still to be undertaken.

Emanating from the recommendations forwarded by the respondents and research cited, it is important to also integrate broader societal aspects. Poverty in particular, that is widespread in South Africa needs to be addressed since this impacts on tourists' experiences and perceptions as well as on how tourism is perceived by locals and if they support the industry. Mega-events in particular can be perceived as a celebration for those who can afford it, while those who cannot participate minimally from the periphery.

Tourism outcomes related to the hosting of mega-events need to be planned, particularly if more widespread benefits are to be realised within the tourism industry and in local communities. The tourism industry needs to capitalise on the positive experiences and images of South Africa. Furthermore, perceptions and experiences of high costs associated with South Africa as a tourist destination needs to be addressed. This is a major negative destination impact of hosting mega-events which are associated with significant price increases, especially in the key accommodation and transport sectors that foreign tourists use. Since South Africa is a longhaul destination, the perception that the country is a costly tourism destination can have neg- 
ative consequences in the long-term. South Africa is unlikely to reap benefits from being exposed to new markets (geographically and in terms of different age groups) during the World Cup if most feel that they cannot afford to visit the country. The once-in-a-lifetime experience needs to be changed to encourage repeat visitation and new visitors to experience other South African tourism products. This implies that an appropriate destination marketing strategy needs to be put into place.

\section{ACKNOWLEDGEMENTS}

The authors would like to acknowledge that the primary data used in the study was part of a broader 2010 National Environment Volunteer Project undertaken jointly with the Department of Environmental Affairs and Tourism World Academy. Their support for this research is much appreciated.

\section{REFERENCES}

Ahmed F, Pretorius L 2010. Mega-events and environmental impacts: The 2010 FIFA World Cup in South Africa. Alternation, 17(2): 274-296.

Alegre J, Cladera M 2006. Repeat visitation in mature sun and sand holiday destinations. Journal of Travel Research, 44: 288-297.

Bassa Z, Jaggernath J 2010. Living close to 2010 stadiums: Residents' perceptions of the 2010 FIFA World Cup and stadium development in Durban, South Africa. Alternation, 17(2): 121-145.

Bob U, Swart K 2010a. Sport events and social legacies. Alternation, 17(2): 72-95.

Bob U, Swart K 2010b. The 2010 FIFA World Cup and women's experiences in fan parks, Agenda, 85: 85-97.

Bureau for Economic Research 2010. The Home Team Scores: A First Assessment of the Economic Impact of World Cup 2010. Bureau for Economic Research Report No. 10. Stellenbosch: University of Stellenbosch.

Chappelet J, Junod T 2006. A tale of 3 Olympic cities: What can Turin learn from the Olympic legacy of other Alpine cities? In: D Torres (Ed.): Major Sport Events as Opportunity for Development. Valencia: Valencia Summit Proceedings, pp. 1-8.

Cornelissen S 2005. The Global Tourism System. Governance, Development and Lessons from South Africa. Aldershot: Ashgate.

Cornelissen S 2010. The geopolitics of global aspiration: Sport mega-events and emerging powers. International Journal of the History of Sport, 27(1617): 1-18.

Cornelissen S, Maennig W 2010. On the political economy of 'feel-good' effects at sport mega-events: Experiences from FIFA Germany 2006 and pros- pects for South Africa 2010. Alternation, 17(2): 96-120.

Cornelissen S, Swart K 2006. The 2010 Football World Cup as a political construct: The challenge of making good on an African promise. In: J Horne, W Manzenreiter (Eds.): Sports Mega-events - Social Scientific Analyses of a Global Phenomenon. Oxford: Blackwell Publishing, pp.108-123.

George R 2003. Tourist's perceptions of safety and security while visiting Cape Town. Tourism Management, 24: 575-585.

George R 2010. Visitor perceptions of crime-safety and attitudes towards risk: The case of Table Mountain National Park, Cape Town. Tourism Management, 31: 806-815.

Getz D 2005. Event Management and Event Tourism. New York: Cognisant Communication Corporation.

Jordaan D 2005. South Africa 2010. Paper presented at the 2010 Communication Launch Workshop. Johannesburg, South Africa. P. 5.

Kirkup N, Major B 2007. Doctoral foundation paper: The reliability of economic impact studies of the Olympic Games: A post-games study of Sydney 2000 and considerations for London 2012. Journal of Sport and Tourism, 11(3-4): 275-296.

Kromberg J 2003. Visitors: Safe and secure. Leadership, Tourism Focus, 1(1): 46-48.

Meethan K 2001. Tourism in Global Society: Place, Culture, Consumption. Malaysia: Palgrave.

Page SJ, Hall CM 2003. Managing Urban Tourism. Harlow: Prentice Hall.

Peeters P, Schouten F 2006. Reducing the ecological footprint of inbound tourism and transport to Amsterdam. Journal of Sustainable Tourism, 14(2): $157-171$

Preuss H 2007. The conceptualisation and measurements of mega sport event legacies. Journal of Sport and Tourism, 12(3-4): 207-227.

Schmied M, Hochfeld C, Stahl H, Roth R, Armbruster F, Türk S, Friedl C 2007. Green Champions in Sport and Environment: Guide to Environmentally-sound Large Sporting Events. Federal Ministry for the Environment, Nature Conservation and Nuclear Safety (BMU), Berlin and German Olympic Sports Confederation (DOSB), Division Development of Sports, Frankfurt. From <http:// www.dosb.de/fileadmin/fm-dosb/arbeitsfelder/umwelt-sportstaetten/Veranstaltungen/Green Champions_Guide_070928.pdf> (Retrieved July 15, 2011).

Simpson PM, Siguaw JA 2008. The role of traveller type, residents, and indentify salience. Journal of Travel Research, 47(2): 167-182.

South Africa Tourism (SAT) 2007. Business Tourism Growth Strategy. From <http://www. southafrica. net/sat/action/media/download File?media_ fileid= 28707> (Retrieved July 15, 2011).

South African Tourism (SAT) 2010. SAT Index: July to September 2010. From <http://www. south africa. net/sat/action/media/download File? media_ fileid= 36812> (Retrieved July 15, 2011).

South African Tourism (SAT) 2011. Highlights of Tourism's Performance in 2010. From <http://www. southafrica.net/sat/action/media/download 
File?media_fileid=116401> (Retrieved July 15, 2011).

Steyn J, De Beer M, Fouché H 2009. In anticipation of the 2010 Soccer World Cup in South Africa: Occurrence of street robberies on Durban's 'Golden Mile’. Acta Criminologica, 22(3): 98-117.

Swart K, Bob U 2004. The seductive discourse of development: The Cape Town 2004 Olympic Bid. Third World Quarterly, 25(7): 1311-1324.

Swart K, Bob U, Turco D 2010. Media, crime and the 2010 Soccer World Cup in South Africa: Pre-event analysis and perceptions. Alternation, 17(2): 225248.

United Nations World Tourism Organisation (UNWTO) (2010) UNWTO World Tourism Barometer, Interim Update, August 2010. From < http://www.arlt-
lectures.com/UNWTOaugust10.pdf $>$ (Retrieved July 28, 2011).

Van der Merwe J 2007. Political analysis of South Africa's hosting of the rugby and cricket World Cups: Lessons for the 2010 Football World Cup and beyond. Politikon, 34(1): 53-66.

Weed M, Bull C 2004. Sports Tourism: Participants, Policy and Providers. Oxford: Elsevier/ Butterworth.

World Travel and Tourism Council (WTTC) 2007. Breaking Barriers - Managing Growth: Summit Highlights 2007. From <http://www.wttc.org/bin/ pdf/ original_pdf_file/summit_report_2007_final. pdf> (Retrieved July 28, 2011). 